\title{
New Hybrid FRP Strengthening Technique for Rectangular RC Columns Subjected to
} Eccentric Compressive Loading

\author{
Worajak Janwaen $^{\mathrm{a}, \mathrm{b}}$, Joaquim A. O. Barros ${ }^{\mathrm{c}}$ and Inês G. Costa ${ }^{\mathrm{d}}$
}

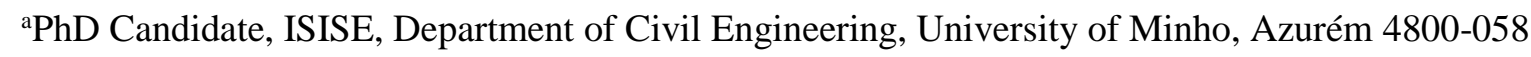

Guimarães, Portugal, tontrakarn.w@gmail.com (corresponding author)

${ }^{\mathrm{b}}$ Lecturer, Department of Civil Engineering, University of Phayao, Thailand

${ }^{\mathrm{c} F u l l ~ P r o f ., ~ I S I S E, ~ D e p a r t m e n t ~ o f ~ C i v i l ~ E n g i n e e r i n g, ~ U n i v e r s i t y ~ o f ~ M i n h o, ~ A z u r e ́ m ~ 4800-058 ~}$

Guimarães, Portugal, barros@civil.uminho.pt

${ }^{\mathrm{d} P h D}$ Civil Eng., CiviTest, Parque Industrial de Jesufrei, Rua da Indústria, n. ${ }^{\circ} 144$, 4770-160 Vila

Nova de Famalicão, Portugal, inescosta@civitest.com

\section{Abstract}

In this work, a new hybrid technique for the strengthening of rectangular reinforced concrete (RC) columns under eccentric compressive loading is described, and its effectiveness is assessed experimentally. This technique combines two carbon fiber-reinforced polymer (CFRP) systems for complementary purposes: strips of CFRP wet-layup sheets with a certain prestress level using a mechanical device in an attempt of introducing an effective concrete confinement; CFRP laminates applied according to the near surface mounted (NSM) technique for increasing the flexural capacity of the RC columns. The effects of the cross-section aspect ratio and flexural strengthening ratio of CFRP laminates were investigated in terms of the load carrying capacity of this type of RC columns. All specimens had a height of $1080 \mathrm{~mm}$, and three cross-sections were considered, $120 \times 120 \mathrm{~mm}^{2}, 240 \times 120$ $\mathrm{mm}^{2}$ and $480 \times 120 \mathrm{~mm}^{2}$, representing cross-section aspect ratios (large/small edge) equal to 1,2 and 4, respectively. All columns were subjected to eccentric compressive loading until failure. The results showed that the new hybrid strengthening technique can enhance the performance of rectangular RC columns in terms of load-carrying capacity and ductility under eccentric loading. The cross-section 
aspect ratio played an important role on the confinement effectiveness of the strengthened system. When

the cross-section aspect ratio increases, the benefits provided by the proposed technique in terms of maximum axial strength and lateral deformability at the peak load of all columns decrease. The load carrying capacity and lateral deformability of the tested RC columns have increased with the flexural strengthening ratio. Moreover, an analytical model is proposed for evaluating the maximum strength and the axial load-lateral displacement response of rectangular RC columns strengthened according to the new proposed technique, and a good predictive performance was obtained.

Keywords: Concrete confinement, RC columns of rectangular cross-section, post-tensioned CFRP wetlayup strips, NSM CFRP laminates, Eccentric compressive loading tests, Analytical model

\section{INTRODUCTION}

Over the last two decades, research and applications in fiber-reinforced polymer (FRP) composites for the strengthening of existing reinforced concrete (RC) structures have demonstrated to be an effective alternative solution to traditional techniques based on conventional materials. The superior characteristics of FRP composites, such as lightweight, high strength-to-weight ratio, corrosion immunity, high durability and easy application, provide many advantages for their utilization in structural strengthening (ACI 2017; Hollaway and Teng 2008). Jacketing RC columns with externally bonded FRP composites is one of the most common and effective application of FRP. This technique introduces lateral confinement to the concrete, increasing the axial compressive strength and axial deformability of RC columns under axial compressive loading. However, this technique is much more effective in columns of circular cross-sections than in columns of rectangular cross-sections (Mirmiran et al. 1998; Harajli 2006; Nisticò 2014).

The application of FRP systems with a certain prestress level has also been investigated for the confinement of concrete columns. Tamuz et al. (2006), Janke et al. (2009) and Ciniņa et al. (2012) adopted a technique where FRPs were wound around concrete cylinder specimens using a stationary yarn winding equipment. From the experimental results, a higher load carrying capacity was obtained for all prestressed confined concrete specimens compared to un-presstressed confined concrete 
specimens. Nevertheless, this technique was only suitable for concrete cylinder columns. Nesheli and Meguro (2005) proposed a prestressed strengthening technique for square RC columns using FRP belts. Five specimens were tested under lateral cyclic loading with a constant axial compression load. The results revealed that the behavior of square cross section RC columns under this type of loading (intended to represent seismic actions) can be improved by using this strengthening technique. Rousakis et al. (2019) proposed an external prestressed strengthening technique for square RC columns by using special mechanical devices combined with basalt and polypropylene fiber ropes, PPER. The results showed that the behavior of the strengthened columns in terms of stress-strain response was significantly improved when compared to the response of their reference columns. However, a high content of wrapping material was required for this technique for ensuring the target strengthening level. However all the aforementioned techniques have been applied to RC columns of circular or rectangular cross section, so their effectiveness on the strengthening of rectangular cross section RC columns was not assessed.

Previous studies have investigated the behavior of concrete columns strengthened with FRP systems when submitted to concentric loading, in order to assess their favorable effects in terms of load carrying capacity and deformation performance of the columns (Rochette and Labossière 2000; Chaallal et al. 2003; Yang et al. 2004; Matthys et al. 2005; Benzaid et al. 2008; Abbasnia et al. 2012; Colajanni et al. 2014; Rousakis and Tourtouras 2014; Zeng et al. 2017). In practical situations, however, RC columns are submitted to axial and flexural loadings, but few studies have been dedicated to investigate the behavior of FRP-strengthened columns under eccentric loads. Hadi (2007a, 2007b) studied the behavior of FRP strengthened concrete columns of circular cross-section under eccentric loading. He found that FRP was very effective in increasing the load capacity and ductility compared to un-strengthened columns. For a strengthened column with normalized load eccentricity of 0.24 (ratio between load eccentricity and cross section diameter, $e / D$ ), strength gains up to 55\% were reported when compared to its reference (un-strengthened) column. El-Maaddawy (2009) carried out an experimental program for assessing the influence of FRP wrapping systems on the structural performance of RC columns of square cross section eccentrically loaded. 
ratio of $0.3,0.43,0.57$ and 0.86 were investigated. The results showed a decrease of the strength gain caused by FRP wrapping with the increase of $e / h$. The compressive strength of the fully wrapped columns was approximately $37,24,8$ and $3 \%$ higher than the reference (unwrapped) columns at nominal $e / h$ values of $0.3,0.43,0.57$ and 0.86 , respectively. However, the partially wrapped columns have presented a compressive strength less than in about $5 \%$ of the fully wrapped columns due to a lower confinement provided by the discrete CFRP wrapping arrangements.

In a subsequent work, Maaddawy et al. (2010) studied the effect of the cross-sectional shape (circular, square and rectangular) on the performance of RC members confined with carbon fiber-reinforced polymer (CFRP) sheets under various loading conditions. The experimental results indicated that the cross-sectional shape had a significant effect on the gain in terms of load capacity and ductility of concentrically loaded members. The concentrically loaded members of circular cross-section exhibited higher gain in terms of these performance indicators compared with the square and rectangular crosssection columns, having this last configuration presented the smallest favorable effects provided by the strengthening technique. For eccentrically loaded members, the experimental results did not show a consistent trend on the effect of the cross-sectional shape on the gain in load capacity. Only a slight effect of the cross-section shape on the ductility of the eccentrically loaded members was obtained. The columns with rectangular cross-section exhibited the lowest improvement in terms of deformation capacity. Moreover, the authors suggested that the effect of the slenderness ratio (length of a column to the least radius of gyration of its cross section) and specimen's size on the performance of CFRPconfined RC members under various loading conditions should be further investigated.

Pan et al. (2007) have also verified that the load carrying capacity of FRP-wrapped concrete columns decreases with the increase of the column's slenderness ratio. Gajdosova and Bilcik (2013) investigated the performance of slender rectangular RC columns strengthened with CFRPs in different configurations, when subjected to eccentric load. In their work, a first group of columns was partially confined with CFRP sheets, a second group was strengthened with CFRP laminates according to near surface mounted (NSM) technique, and a third group was strengthened with a technique combining the two previous ones. For each group of columns, slenderness ratios of 25, 48, 71, 98 and 118 of columns were also investigated. The length in the evaluation of slenderness ratio was considered as the distance 
112 between the extremities of the column that are connected to the equipment with mechanical hinges. The

113 results revealed that the CFRP confinement system had only a significant influence in the column's

114 strength for the short RC columns. No significant effect in column's performance with the increase in

115 slenderness was obtained. For instance, in columns strengthened with CFRP sheet, the strength

116 enhancement (maximum load capacity of strengthened to non-strengthened RC columns ratio) was

$11710 \%, 7 \%, 2 \%, 1 \%$ and $1 \%$ for the columns with slenderness ratio of $25,48,71,98$ and 118 , respectively.

118 The use of NSM CFRP laminates was very effective when the flexural behavior dominates the response

119 of slender columns, as was already demonstrated in previous experimental programs and numerical

120 simulations (Barros et al. 2008; Perrone et al. 2008). In conclusion, the combination of CFRP wrapping

121 and NSM CFRP laminates is the most effective method for enhancing the load carrying capacity of slender RC columns subjected to eccentric loading. Moreover, combining these strengthening techniques and adopting and adequate reinforcing ratio of NSM CFRP laminates and a CFRP wrapping ratio, the increase of flexural strengthening and energy dissipation can be conveniently tailored (Perrone et al. 2008; Chellapandian et al. 2017).

The present work is the second phase of a research project aiming to explore the potentialities of a new CFRP-based strengthening technique for increasing the structural performance of RC columns of rectangular cross section. This technique, designated by strip constriction (SC), is based on the concept of applying strips of CFRP wet layup sheets with a certain prestress level (approximately $20 \%$ of the ultimate strain of the CFRP sheet) by means of a mechanical device (Janwaen et al. 2019). In the first phase of this research project, the SC was applied to RC columns subjected to concentric loading, and the experimental results shown that the SC technique is more efficient than CFRP-based conventional strengthening technique (fully or partially confined with CFRP) in terms of increasing the load carrying capacity of rectangular RC columns. When compared to the corresponding reference column, the increase in terms of strength gain provided by the SC technique was $25 \%$ and $32 \%$ in the columns of cross section aspect ratio $(\lambda)$ of 2 and 4 , respectively, being $\lambda$ the large/small edge ratio of the cross section. However, the columns fully and partially confined with CFRP provided a strength gain limited to a range between $7 \%-23 \%$. In addition, the compressive strength and ultimate axial strain for all strengthened groups of columns with different $\lambda$ have decreased with the increase of cross-section 
aspect ratio. However, the columns strengthened according to the SC technique showed a lower

141 decrease of compressive strength with the increase of $\lambda$ compared to the columns strengthened by the

142 other strengthening techniques. It was also verified that the SC technique is not only technically efficient, but also cost competitive, since the increase of load carrying capacity per quantities of CFRP strengthening material was higher in the SC technique than in the other strengthening techniques.

In this second phase of the research project, the SC technique is combined with the NSM technique, where CFRP laminates are disposed into grooves on the concrete cover of the faces of the column subjected to tension, in order to enlarge the SC potentialities for the flexural strengthening of RC columns of rectangular cross section. This new technique is herein designated by Hybrid Strip Constriction (HSC). The influence of the $\lambda$ and the strengthening ratio of longitudinal CFRP laminates on the strength and deformation capacity of this type of RC columns was investigated. Moreover, an analytical model is proposed for predicting the maximum strength and load-lateral displacement response of RC columns strengthened with the HSC technique, and its predictive performance is assessed. The experimental program and the analytical model are detailed, and the relevant results are presented and discussed in the following sections.

\section{EXPERIMENTAL PROGRAM}

\subsection{Specimen details}

The experimental program is composed of $12 \mathrm{RC}$ column specimens of rectangular cross-section to investigate the effectiveness of the HSC technique when submitted to eccentric compressive loading of 0.15 eccentricity-to-section height $(e / h)$ ratio. This value for $e / h$ was selected for assessing the effectiveness of the proposed technique since it represents current load conditions of columns of RC frames. The experimental program was designed in order to assess the influence of the column's cross section aspect ratio $(\lambda=h / b)$ and the flexural strengthening ratio, $\rho_{f l}$, on the strengthening effectiveness of the HSC technique. The $\lambda$ is the ratio between the larger $(h)$ and smaller $(b)$ dimension of the column's cross section, while $\rho_{f l}=A_{f l} / b d_{f}$ is the strengthening ratio provided by the 
sectional area of the CFRP laminates in tension and their internal arm, respectively. The columns of this experimental program have cross section of $120 \times 120 \mathrm{~mm}^{2}, 240 \times 120 \mathrm{~mm}^{2}$ and $480 \times 120 \mathrm{~mm}^{2}$, representing a $\lambda$ of 1,2 and 4 , respectively. This experimental program is organized in order to have: (1) Columns without any type of strengthening, considered as reference columns (REF); (2) Columns strengthened according to the HSC technique with one CFRP laminate (HSC-1L); and (3) Columns strengthened according to the HSC with two CFRP laminates (HSC-2L). All specimens have a height of $1080 \mathrm{~mm}$, and all strengthened columns have a corner radius of $25 \mathrm{~mm}$ to minimize the possibility of premature failure of the CFRP wet-layup strips in these zones (Shan et al. 2017). The strengthened columns are confined with three layers of CFRP wet-layup sheet per strip. Due to the high stress field developed at the extremities of the column, five layers of CFRP sheet of $80 \mathrm{~mm}$ width were applied in these zones in an attempt of preventing premature concrete crushing. The geometry, reinforcement and strengthening arrangements of the columns of the experimental program are indicated in Figs. 1 and 2. To identify the strengthened specimens, the columns are labeled as " $\lambda \mathrm{X}-\mathrm{HSC}-\mathrm{Y}$ ", where $\lambda$ represents the cross-section aspect ratio $(h / b)$ and therefore $\mathrm{X}$ can assume the values of 1,2 and 4; Y can be replaced by $1 \mathrm{~L}$ or $2 \mathrm{~L}$ and represents the number of CFRP laminates applied according to the NSM technique in the shorter sides of the column's cross section. For example, $\lambda 1-\mathrm{HSC}-2 \mathrm{~L}$ is the column with a cross-section aspect ratio of 1 , strengthened with two NSM CFRP laminates in the shorter sides of the column. The reference specimens are identified by " $\lambda X-R E F "$. The adopted steel reinforcement configurations, mainly in terms of percentage and spacing of steel hoops, present some of the type of debilities found in RC columns of relatively high percentage of frame buildings designed without attending properly to actual design seismic demands. This type of situation is current in several countries in high seismic risk zones. Therefore, an important objective of the present work is to assess the potentialities of the proposed strengthening technique for this type of RC columns. The CFRP strips applied with a certain prestress level in between existing steel hoops aim to increase the concrete confinement, while the CFRP laminates introduced in the concrete cover of the column's faces in tension have the purpose of increasing the flexural capacity of the column. 


\subsection{Material Properties}

195 The columns used in this experimental program were prepared simultaneously with materials used in the specimens tested in the previous phase of this research project. Therefore, a comprehensive material characterization can be found elsewhere (Janwaen et al. 2019). The average concrete compressive strength assessed on concrete cylinder specimens of $150 \mathrm{~mm}$ diameter at 28 days was $21 \mathrm{MPa}$. For the conventional steel reinforcement and CFRP sheet, the main properties are indicated in Tables 1 and 2, respectively. For the steel reinforcement, the tensile properties were obtained according to the ISO 6892-1 recommendations (ISO 2009a). Table 2 includes the characteristic values of the properties of the CFRP sheet, which were provided by the manufacturer, where the mechanical properties were determined by direct tensile tests according to ISO 572-5 recommendations (ISO 2009b). For the NSM strengthening, S\&P CFRP pultruded laminates were used, with $2.5 \times 15 \mathrm{~mm}^{2}$ cross section, which according to the supplier have characteristic values of $170 \mathrm{GPa}$ and $2800 \mathrm{MPa}$ for the modulus of elasticity and a tensile strength, respectively. For the installation of the CFRP laminates, grooves of 7.5 $\mathrm{mm}$ width and $15 \mathrm{~mm}$ depth were executed in the concrete cover, which has a thickness of $20 \mathrm{~mm}$, and S\&P 220 epoxy adhesive was used to bond the CFRP laminates to the concrete. An average tensile strength of $20 \mathrm{MPa}$ and an elasticity modulus of $7 \mathrm{GPa}$ was determined for this adhesive by Costa and Barros (Costa and Barros 2015) by carrying out direct tensile tests according to ISO 527-2 (ISO 1993).

\subsection{Hybrid strengthening technique}

The HSC consists on combining the NSM strengthening technique using the CFRP laminates indicated in the previous section, with the SC technique that was for the first time proposed in (Janwaen et al. 2019). The NSM CFRP laminates have the purpose of assuring the required increment of flexural capacity for the RC columns, while the SC technique introduces an active confinement effect in the concrete due to the post-tension applied in the CFRP wet-layup strips that wrap the column (Fig. 2). Being confined by the CFRP strips, the buckling of the NSM-CFRP laminates are significantly prevented. recommendations. For applying the HSC technique, the following procedures are executed (Fig. 2). 

$\mathrm{mm}$ of depth were opened on the concrete cover of the shorter edges of the column's cross section, along the total height of the column for the installation of one CFRP laminate per groove. The grooves were cleaned using compressed air to remove dust and loose particles. The two-component S\&P 220 epoxy adhesive indicated in Section 2.2 was then prepared with a mixing ratio of 4:1 (resin:hardener), following the recommendations of the supplier. By using a spatula, the adhesive was introduced into the grooves, which was assured to be in dry conditions. The CFRP laminates, previously cut in the desired length and cleaned with acetone, were inserted in the grooves, and the excess adhesive coming out from the grooves was removed with a spatula to smooth the surface. All NSM strengthened specimens were left to dry at least 7 days in laboratory environment before subsequent strengthening with the SC technique. Strips of wet-layup CFRP sheet were applied on the concrete surface according to the geometric layout shown in Fig. 1 (in between steel hoops in an attempt of maximizing the confinement effect). Next, a threaded rod, round D shaped steel bars, nuts and washers were assembled together on the column. The intended post-tension to the CFRP strips was applied by screwing the nuts with a dynamometric wrench, which forced the D-shaped steel bars to push the CFRP strips toward the grooved section, inducing the intended stress level in the CFRP strips. The dynamometric wrench was initially calibrated in order to have a correspondence between the applied torque and the level of strain introduced in the CFRP strip. For this purpose, the wrench was gradually screwed, and the torque from the wrench and the strain in the CFRP were monitored up to the attainment of the target strain in the CFRP strip (20\% of its ultimate strain). At this target strain, the torque read in the wrench was $48.8 \mathrm{~N}$ $\mathrm{m}$, which was set the target torque for this experimental program. In this state, the D-shaped steel bars did not touch the surface of concrete, therefore, they do not introduce directly any compressive stress on the concrete, being the concrete confinement exclusively ensured by CFRP strips. More details regarding the SC strengthening technique can be found elsewhere (Janwaen et al. 2019).

2.4 Test setup and monitoring systems

A representation of the experimental setup for testing the $\mathrm{RC}$ column specimens under eccentric compressive loading is shown in Fig. 3. Pinned support conditions were provided to both extremities 
of the column for allowing their free rotation. Both bottom and top surfaces of all columns were capped with polyester paste to ensure full contact between these surfaces and the steel loading plates, and therefore uniform load transference. A loading system was designed and manufactured for assuring pinended eccentric loading conditions to the specimens. This system consisted of a solid V-shape steel plate welded to a steel cylinder, which pivots on a steel plate of $40 \mathrm{~mm}$ thick in a notch located at the intended eccentricity (Fig. 3). These two parts were assembled in order to allow the rotation of the extremities of the column around the aforementioned notch. Preliminary tests have demonstrated that no relative lateral displacement occurred between the supports. Additionally, two L steel profiles contacting the two opposed smaller surfaces of the column were embraced with steel rods for providing additional concrete confinement to the column's extremities. This aims to prevent premature failure of the columns due to the occurrence of severe local damage (Fig. 3). To analyze the overall behavior of the columns, the axial deformation and the lateral deflection were measured using Linear Voltage Displacement Transducers (LVDTs). Six LVDTs were installed along the smaller faces of the column to evaluate the axial deformation in the central region of the column, covering a length of $600 \mathrm{~mm}$. In addition, two LVDTs were used to measure the lateral deflection at mid-height and at quarter-height of the column. All specimens were tested under eccentric compression with a closed-loop servo-controlled compression machine with a load cell of $2000 \mathrm{kN}$ capacity. Data read from LVDTs and load cell were recorded at the same time using a data acquisition system. In an attempt of capturing the post-peak behavior of the columns, a displacement control protocol was used with a relatively slow displacement rate of $0.3 \mathrm{~mm} / \mathrm{min}$, controlled by the internal LVDT of the servoactuator.

\subsection{Experimental results and discussion}

\subsubsection{Load carrying capacity}

274 A summary of the obtained experimental results is presented in Table 3, where: $e$ is the load eccentricity; $P_{\max }$ is the maximum compressive load supported by the column; $u_{\max }$ is the lateral 
by the HSC technique (with reference to the un-strengthened column of the corresponding series). From the experimental results, it is verified that, when compared to the $\lambda 1-\mathrm{REF}$ reference column, an increase of $9 \%$ and $34 \%$ in the maximum load was obtained in the $\lambda 1-\mathrm{HSC}-1 \mathrm{~L}$ and $\lambda 1-\mathrm{HSC}-2 \mathrm{~L}$, respectively. When compared to the $\lambda 2-\mathrm{REF}$ column, this increase was $21 \%$ and $33 \%$ in the columns $\lambda 2-\mathrm{HSC}-1 \mathrm{~L}$ and $\lambda 2-\mathrm{HSC}-2 \mathrm{~L}$, respectively, while an increase of $19 \%$ and $23 \%$ was registered in the $\lambda 4-\mathrm{HSC}-1 \mathrm{~L}$ and $\lambda 4$-HSC-2L when compared to the $\lambda 4$-REF. Therefore, the HSC technique has increased the overall load carrying capacity, even though the strengthening performance tends to decrease with the increase of $\lambda$. The column's load carrying capacity has increased with the number of NSM-CFRP laminates, but its influence on the strengthening performance (compressive strength gain) has decreased with the increase of $\lambda$.

\subsubsection{Failure modes}

The aspect, after failure, of the eccentrically loaded RC columns with cross-section aspect ratio equal to $1(\lambda 1), 2(\lambda 2)$ and $4(\lambda 4)$ are shown in Figs. 4 to 6 . In the case of un-strengthened RC columns $(\lambda 1$ REF, $\lambda 2-\mathrm{REF}$ and $\lambda 4-\mathrm{REF}$ ), the failure of the columns generally occurred by a sudden loss of concrete cover, followed by the buckling of the longitudinal reinforcing bars at the compression side. For $\lambda 1$ REF and $\lambda 2$-REF, small cracks could be observed before peak load, which have continued propagating until the failure. However, no cracks could be seen on $\lambda 4$-REF before the peak load due to the small lateral deflection in consequence of the relatively high flexural stiffness of this column. The failure regions of $\lambda 1-\mathrm{REF}$ and $\lambda 2$-REF were close to the mid-height of the columns, while the failure of $\lambda 4-$ REF occurred near the extremities of the columns, mainly in the one in contact with the actuator, due to the high stress concentration in this region.

Regarding the columns strengthened according to the new technique, they failed, generally, by the occurrence of one, two or all of the three following damage mechanisms: 1) crushing of concrete; 2) rupture of CFRP strips; and 3) rupture of CFRP laminates. For the $\lambda 1$ group of strengthened columns ( $\lambda 1$-HSC-1L, $\lambda 1$-HSC-2L), Fig. 4, the failure mechanism of the columns was the same, regardless the percentage of CFRP laminates. The failure occurred suddenly by an explosive crushing of concrete in 
one of the zones in-between CFRP wet layup strips (first or second from the column's loaded extremity), followed by the rupture of CFRP laminates in the compression face (due to local buckling in consequence of the local loss of confinement provided by the surrounding concrete in crushing stage). There was no rupture of CFRP laminates in the tensile face. Nevertheless, small cracks could be observed in the concrete tensile face. The column with the lowest percentage of CFRP laminates ( $\lambda 1$ HSC-1L) has gradually failed after reaching its maximum load capacity. Then, severe spalling of concrete cover occurred at approximate $90 \%$ of peak load in the post peak stage, followed by the compressive rupture of the CFRP laminate in the compression face. For the $\lambda 1-\mathrm{HSC}-2 \mathrm{~L}$, crushing of concrete and the compressive rupture of CFRP laminates occurred simultaneously at its maximum load capacity. After this failure point, a sudden decrease of load capacity was observed, accompanied by a large increase of lateral displacement. The buckling of the reinforcing bars and the rupture of CFRP strips could not be observed in all the columns of the $\lambda 1-\mathrm{HSC}$ until the test was finished.

In case of the strengthened columns with the cross-section aspect ratio of 2 ( $\lambda 2-\mathrm{HSC}-1 \mathrm{~L}, \lambda 2-\mathrm{HSC}-2 \mathrm{~L})$, all the above three types of failures were observed. The failure mechanism was the same in both $\lambda 2-$ HSC-1L and $\lambda 2$-HSC-2L columns: explosive crushing of concrete and rupture of CFRP strips at peak load, followed by the compressive rupture of CFRP laminates, which led to a decrease of the applied load. The failure region was close to the mid-height of the columns, where the maximum bending moment occurs due to second order effects.

For $\lambda 4$ group, it was found that the failure modes of the columns in this group were different from the ones of the two previous groups. The second order effect of the eccentric load was much less pronounced because the maximum lateral deflection was marginal compared to the ones registered in the two previous groups. Fig. 7 shows that the mid-height deflection at the rupture of the strengthened columns of $\lambda 4$ group was about $1.8 \mathrm{~mm}$, while in the $\lambda 1$ group has varied between $8.0 \mathrm{~mm}$ to $14.5 \mathrm{~mm}$, and in the $\lambda 2$ group has varied between $4.9 \mathrm{~mm}$ to $7.7 \mathrm{~mm}$. The lateral mid-height deflection has increased with the number of CFRP laminates. The failure of the strengthened columns of the $\lambda 4$ group was mainly caused by concrete crushing in the unconfined zone in-between the two groups of CFRP strips on the top extremity of the columns. As it is shown in Fig. 6, a brittle rupture of the unconfined 
concrete has occurred in the columns of the $\lambda 4$ group, which has avoided the mobilization of the flexural stiffness of these columns.

333 Based on these experimental tests, it can be noted that the failure of columns depends on the column's cross section-aspect ratio and flexural strengthening ratio. The buckling of the reinforcing bars was found in REF columns ( $\lambda 1-\mathrm{REF}, \lambda 2-\mathrm{REF}$ and $\lambda 4$-REF), with marginal evidence of its occurrence in the strengthened columns due to the resistance offered by the CFRP wet-layup strips applied with a certain post-tension. By decreasing the cross-section aspect ratio, the damage causing the rupture tends to be localized in the center of the column due to the relatively high second order effect of the eccentric load. The flexural stiffness of the $\lambda 4$ columns was too high when compared to the bending moment introduced by the eccentric load, and therefore, failure was not governed by this effect. In order to avoid a local failure at column's extremities, confinement systems of adequate stiffness should be designed and disposed in these regions, and the thickness of the steel plate adopted to transfer the load from the actuator to the column should be sufficiently enough for ensuring the target eccentric compressive loading ratio. Both the stiffness of these confinement arrangements and the thickness of the steel plate should increase with the column's cross-section aspect ratio.

\subsubsection{Load-Lateral displacement response}

The relationships between the applied load and the lateral displacement at mid-height of the tested columns are shown in Fig. 7. All strengthened columns exhibited higher load capacity and lateral deformability (ductility) compared to their corresponding reference columns. In all the series, the column's maximum load increased with the flexural strengthening ratio provided by the CFRP laminates. The same happened in terms of mid height lateral displacement at peak load. The flexural strengthening ratio had, however, small influence in this deflection performance in the $\lambda 4$ series due to the relatively high flexural stiffness of the columns of this series. All the strengthened columns presented a nonlinear response before the peak load, with an amplitude that has decreased with the increase of $\lambda$. The higher mobilization of the flexural stiffness, combined 
with a more active contribution of the NSM-CFRP laminates shows that for lower $\lambda$ values, the nonlinear branch before peak load is enlarged.

Apart from $\lambda 1$-HSC-1L column, in the remaining columns of $\lambda 1$ and $\lambda 2$ series, an abrupt load decay has occurred at the peak load due to concrete crushing, followed by the compressive rupture of the NSM CFRP laminates in the compression face. In the $\lambda 1-\mathrm{HSC}-1 \mathrm{~L}$ column, after the peak load, a smooth softening stage was observed, up to the occurrence of the compressive rupture of the NSM CFRP laminate, which is followed by an abrupt load decay.

As expected, the NSM CFRP laminates had marginal contribution for the stiffness of the tested columns. Their main role is to increase the load carrying capacity and lateral deformability at peak load. Just after the compressive rupture of the NSM CFRP laminates, the structural softening modulus of the strengthened columns (ratio between load decrease and lateral displacement increase) was similar to the corresponding reference column. However, in this softening stage, at a load level of about $65 \%$ of the maximum load, series $\lambda 1$ exhibited a more ductile response, which may have been caused by a more effective contribution of the confinement in the extremities of the columns (Fig. 4). This effect was not visible in the $\lambda 2$ series up to the interruption of the tests, since in the columns of this series the wetlayup CFRP strips near the damaged zone have ruptured (Fig. 5).

In terms of lateral mid-height displacement at maximum load, $u_{\max }$, the strengthened columns have presented values of $u_{\max }$ larger than of their corresponding reference columns. The lateral mid-height displacement at maximum load has also increased with the number of NSM-CFRP laminates. However, except $\lambda 1$-HSC-1L column, all remaining exhibited a brittle behavior just after the maximum load has been attained. In the $\lambda 1-\mathrm{HSC}-1 \mathrm{~L}$ column, a gradual failure was observed after reaching its maximum load capacity, which is reflected in the relatively large amplitude of the smooth softening branch response. However, like in the $\lambda 1$-HSC-2L specimens, an abrupt load decay has occurred in the $\lambda 1-$ HSC-1L, but of smaller amplitude, which is a consequence of the smaller load carrying capacity of $\lambda 1$ HSC-1L specimen. 
384 Table 4 presents a summary of the experimental results for evaluating the effect of cross-section aspect

385 ratio of the columns strengthened according to the HSC technique. In this table, $A_{\text {eff }}$ is the effective 386 column's cross-section (after the treatment for the strengthening process); $\sigma_{c c, \max }$ is the axial 387 compressive stress at $P_{\max }\left(\sigma_{c, \text { max }}=P_{\max } / A_{e f f}\right) ; \sigma_{c c, \max }^{S t r} / \sigma_{c c, \max }^{R e f}$ is the strength gain of the column, calculated as the ratio between the compressive strength of a strengthened column and its corresponding reference column (for the columns flexurally strengthened with two laminates, $\sigma_{c c, \max }^{\text {Str }}$ represents the

390 average value); and $\Delta \sigma_{c c, \max }^{S t r, \rho_{f l}}$ is the difference of the strength gain between columns strengthened with two and one CFRP laminates.

The results in Table 4 and in Fig. 8 show that, despite the benefits of the adopted strengthening technique, the compressive strength of the columns of the three series have a decrease of $\sigma_{c c, \max }$ with the increase of $\lambda$. This decrease was not, however, so pronounced in the series of columns strengthened with 1 NSM CFRP laminate, which can be justified by the type of failure mode occurred in the columns of this series. In fact, as explained previously, since the wet-layup CFRP strips have not failed, the confined concrete has contributed for this smaller impact of the $\lambda$ in the compressive strength gain. When analyzing the influence of $\lambda$ in the parameter $\sigma_{c c, \max }^{S t r} / \sigma_{c c, \max }^{\operatorname{Ref}}$ (Fig. 9), which considers the compressive strength of the reference column of the corresponding series (herein designated as normalized compressive strength gain), it is verified that the $\sigma_{c c, \max }^{S t r} / \sigma_{c c, \max }^{\operatorname{Ref}}$ has increased from $\lambda 1$ to $\lambda 2$, and remained almost constant from $\lambda 2$ to $\lambda 4$. The increase of $\sigma_{c c, \max }^{S t r} / \sigma_{c c, \max }^{R e f}$ from the $\lambda 1$ to $\lambda 2$ can be justified by the full activation of the tensile capacity of wet-layup CFRP strips in the failure region of the columns of series $\lambda 2$.

404 Finally, it is observed that $\Delta \sigma_{c c, \max }^{S t r, \rho_{f l}}$ has decreased with the increase of $\lambda$, as expected. In fact, when the 
406 increase a targeted $\Delta \sigma_{c c, \max }^{S t r}$. The very small value of $\Delta \sigma_{c c, \max }^{S t r, \rho_{f l}}$ for the $\lambda 4$ series is justified by the

407 failure modes observed in the columns of this series, since they have avoided an efficient activation of 408 the NSM CFRP laminates. Therefore, for RC columns of relatively large $\lambda$, the use of higher flexural 409 strengthening ratios should be explored (higher number of laminates and/or laminates of larger cross 410 sectional area), but the strengthening effectiveness must be weighed against the costs of the technique.

412 3. A MODEL FOR PREDICTING THE LOAD-DEFORMATION RESPONSE OF RC 413 COLUMNS STRENGTHENED ACCORDING TO THE HSC TECHNIQUE AND 414 ECCENTRICALLY LOADED

\section{$415 \quad 3.1$ Introduction}

416 This section is devoted to the development of a model for predicting the load versus lateral deflection 417 up to the failure of rectangular cross section RC columns strengthened according to the hybrid strip relevant behavioral aspects of this type of structural elements.

Since this type of RC column is submitted to eccentric compressive load, which introduces second order effects on its flexural response, the model must consider the constitutive laws of the intervenient materials, an updated lateral deflection configuration during the loading process, and an approach at cross section level capable of determining a realistic strain-stress field, such is the case of a layer model approach (Barros et al. 2015). The model hereafter presented integrates these functionalities.

\subsection{Constitutive laws of the intervenient materials}

The stress - strain relationship for the concrete, steel and CFRP reinforcements are provided, by using for their characterization the values obtained in the respective experimental tests, provided in Section 
432 diagram represented in Fig. 10. For the compression domain, the formulation proposed by Popovics

433 (1973) was expressed in Eqs (1)-(3).

$434 \quad \sigma_{c}=\frac{f_{c c}^{\prime} x r}{r-1+x^{r}}$

$435 x=\frac{\varepsilon_{c}}{\varepsilon_{c c}^{\prime}}$

$436 \quad r=\frac{E_{c}}{E_{c}-\frac{f_{c c}^{\prime}}{\varepsilon_{c c}^{\prime}}}$

$437 \quad E_{c}=4730 \sqrt{f_{c o}^{\prime}}(\mathrm{MPa})$

438 where $\sigma_{c}$ is the compressive stress of concrete, $f_{c c}^{\prime}$ is the compressive strength of confined concrete,

$439 \varepsilon_{c}$ is the compressive strain of concrete, $\varepsilon_{c c}^{\prime}$ is the confined compressive strain at $f_{c c}^{\prime}, E_{c}$ is the young 440 modulus of concrete and $f_{c o}^{\prime}$ is the compressive strength of unconfined concrete.

441 For evaluating the $f_{c c}^{\prime}$, the formulation in the annex proposed by Janwaen et al. (2019) was adopted. 442 According to this approach, a rectangular cross section of a column strengthened with the proposed 443 technique is regarded as a set of parallel square cells, as described in detail elsewhere (Janwaen et al. 444 2019).

445 To calculate the $\varepsilon_{c c}^{\prime}$, the empirical equation proposed by Mander et al. (1988) is adopted:

$446 \quad \varepsilon_{c c}^{\prime}=\varepsilon_{c o}\left[1+5\left(\frac{f_{c c}^{\prime}}{f_{c o}^{\prime}}\right)\right]$

447 where $\varepsilon_{c o}$ is the strain corresponding to $f_{c o}^{\prime}$.

448 For modelling the concrete in tensile behavior (Fig. 10), a bilinear stress-strain diagram is used, where

449 the stiffness of the first branch is defined by the $E_{c}$, and the concrete tensile strength is determined

450 from:

$451 \quad f_{c t}^{\prime}=0.3\left[f_{c o}^{\prime}\right]^{\frac{2}{3}}$ 


$$
|\chi|=\left|\frac{\partial^{2} u}{\partial z^{2}}\right|=\left(\frac{\pi^{2}}{L}\right) u_{m} \sin \left(\frac{\pi z}{L}\right)
$$

\subsection{Formulation}

$$
u(z)=u_{m} \sin \left(\frac{\pi z}{L}\right)
$$

while the tensile strain softening stage is simulated by a linear branch up to the ultimate tensile strain ( $\left.\varepsilon_{t u}\right)$, assumed equal to 10 times the strain at crack initiation $\left(\varepsilon_{t c r}=f_{c t}^{\prime} / E_{c}\right)$ (Liang 2011).

The behavior in compression and tension of the steel reinforcement was assumed the same, and simulated by a linear stress-strain diagram up to the strain at yield initiation of the steel, $\varepsilon_{s y}$ (or stress at yield initiation of the steel, $\sigma_{s y}$ ), defined by the steel elasticity modulus, $E_{s}$, followed by a rigid plastic stage up to the ultimate strain, $\varepsilon_{s u}$.

Finally, the NSM CFRP laminates are considered behaving as linear-elastic brittle materials in both compression and tension, defined by the longitudinal modulus of elasticity (in the direction of the fibers), $E_{f}$, and their effective strain level in the FRP laminate at the ultimate limit state, $\varepsilon_{f e}$, in which $\varepsilon_{f e}=0.6 \times \varepsilon_{f u}$, where $\varepsilon_{f u}$ is the ultimate strain of CFRP laminate (ACI 2017), above which these reinforcements are considered non active (failed in compression or tension).

Due to the eccentric compressive load, the column is subjected simultaneously to axial compressive load and bending moment, and this last one is increasing with the applied load due to the continuous lateral deformability of the column (Fig. 11). The tested columns are assumed as pin-ended, with a lateral deformation simulated by a single bending curvature represented by the following equation:

where $u_{m}$ is the deflection at the mid-height of the column, and $L$ is the effective length of the column. The absolute value of the curvature $(|\chi|)$ of the column can be obtained from the following equation: 
$474 \quad \chi_{m}=\left(\frac{\pi^{2}}{L}\right) u_{m}$

475 In its turn, the applied moment in this section is obtained from:

$476 \quad M=P\left(e+u_{m}\right)$

477 where $e$ is the load's eccentricity length.

478

479 For evaluating the curvature corresponding to the applied load, $P$, and its corresponding bending 480 moment in the section at mid-height of the column, $M$, (Eq. 10), a layered cross section approach is adopted (Fig. 12). The position of the neutral axis of the cross section, $d_{n}$, is obtained by respecting the 482 strain compatibility of the materials (perfect bond of the reinforcements to the surrounding concrete is 483 assumed):

484

$\varepsilon_{c, i}=\chi\left(d_{n}-d_{i}\right)$

485

$\varepsilon_{s, j}=\chi\left(d_{n}-d_{j}\right)$

486

$\varepsilon_{f, k}=\chi\left(d_{n}-d_{k}\right)$

by considering the constitutive laws of the intervenient materials (previously described), and the equilibrium conditions:

489

$P=\sum_{i=1}^{m} \sigma_{c, i} A_{c, i}+\sum_{j=1}^{n} \sigma_{s, j} A_{s, j}+\sum_{k=1}^{o} \sigma_{f, k} A_{f, k}$

490

$M=\sum_{i=1}^{m} \sigma_{c, i} A_{c, i}\left(\frac{h}{2}-d_{i}\right)+\sum_{j=1}^{n} \sigma_{s, j} A_{s, j}\left(\frac{h}{2}-d_{j}\right)+\sum_{k=1}^{o} \sigma_{f, k} A_{f, k}\left(\frac{h}{2}-d_{k}\right)$

In Eqs. (11) to (13) $\varepsilon_{c, i}, \varepsilon_{s, j}$ and $\varepsilon_{f, k}$ are the strain of concrete layer $i$, steel layer $j$ and CFRP

laminate layer $k$, respectively; $\chi$ is the curvature of the composite section; $d_{i}, d_{j}$ and $d_{k}$ are the depth of concrete layer $i$, steel layer $j$ and CFRP laminate layer $k$, respectively (Fig. 12).

In Eqs. (14) and (15) $\sigma_{c, i}, \sigma_{s, j}$ and $\sigma_{f, k}$ represent the stress at the centroid of concrete layer $i$, steel 
concrete layer $i$, steel layer $j$ and CFRP laminate layer $k$, respectively; and $m, n$ and $o$ are,

497

498

499

500

501

502

503

504

505

506

507

508

509

510

511

512 respectively, the total number of concrete, steel and CFRP layers.

The incremental and iterative algorithm is described in the flowchart represented in Fig. 13.

\subsection{Assessment of the predictive performance of the model}

In this section, a comparison between analytical and experimental results is presented. The analytical model presented in the previous section was implemented in a computer program in order to analyze RC columns strengthened according to the HSC technique under eccentric loading.

\subsubsection{Maximum load capacity and corresponding lateral mid-height displacement}

Table 5 compares the maximum compressive load and corresponding lateral mid-height displacement registered experimentally and obtained with the analytical model. For the columns with $\lambda=1$ and 2 , the model provides safe predictions in terms of maximum load capacity, with an average error of about $3 \%$. In terms of lateral mid-height displacement at the maximum load, the model has a tendency to predict higher values, with an average error of $26 \%$.

In case of the columns with $\lambda=4$, the model overestimates both the maximum load and its corresponding lateral deflection, which is justified by the failure modes occurred in this series of columns.

In fact, Fig. 6 shows that the rupture of the $\lambda 4$ columns is caused by the attainment of the compressive strength of concrete in the first unconfined zones from the extremities of the columns. To estimate the load capacity of the columns in these circumstances, the effective width $\left(b_{e f}\right)$ of the mobilized compression area in the $\lambda 4$-REF column is estimated by assuming that in this column, the critical plane is localized at the mid distance between the steel hoops (therefore $\theta_{1}=\arctan (140 / 168) \cong 40^{\circ}$ ), as represented in Fig. 14. By considering that the concrete compressive strength is $21 \mathrm{MPa}$ and the maximum load in this column was $891.56 \mathrm{kN}$, a $b_{e f}=354 \mathrm{~mm}$ is obtained $\left(b_{e f} \times 120 \mathrm{~mm} \times 21 \mathrm{MPa}=\right.$ $891560 \mathrm{~N})$, and consequently $\theta_{2}=\arctan (140 / x) \cong 37^{\circ}$, where $x=b_{\text {ef }}-168=186 \mathrm{~mm}$. 
For the strengthened columns of this series, $\lambda 4$-HSC, and from the analysis of the failure mode observed in these columns (Fig. 6), it is assumed that the critical plane is in-between the bottom border of the

524 first CFRP strip system and the below closest steel hoop (Fig. 15). In these circumstances $\theta_{1}=\arctan (215 / 168) \cong 52^{\circ}$, and assuming for $\theta_{2}$ the value registered in the $\lambda 4-\operatorname{REF}\left(37^{\circ}\right)$, the

$527=1142 \mathrm{kN}$. If an interval for the $\theta_{2} \in\left[37^{\circ}-40^{\circ}\right]$ is adopted, which is totally admissible due to the simple idealization of the failure mechanism, the following interval for the maximum load is determined $F_{\max } \in[1069-1142] \mathrm{kN}$, which is quite close to the values registered in the experimental tests $F_{\max }^{\exp } \in[1062-1123] \mathrm{kN}$.

Therefore, in the proposed analytical model, when $b_{e f}$ is smaller than the largest edge of the column's cross section, which is only verified in the series $\lambda 4$, the maximum load is estimated according to the process just described.

\subsubsection{Load-lateral mid-height displacement}

A comparison of load - lateral mid-height displacement between the experimental and analytical results for RC columns strengthened according to the proposed technique is illustrated in Figs. 16 to 18. For the columns with $\lambda=1$ and 2 the model has predicted the experimental response with high accuracy, even for the post peak stage. For the series $\lambda=4$, taking into consideration the particular failure mode observed in these columns, a limit of the maximum load $\left(F_{\max }\right)$ was adopted by calculating $F_{\max }$ according the methodology described in section 3.4.1 and considering for $\theta_{2}$ the average value of the determined interval $\left(\theta_{2}=39^{\circ}\right)$. By following this methodology, the design approach is also capable of estimating with good accuracy, not only the maximum load, but also the corresponding lateral midheight displacement. 


\section{CONCLUSIONS}

547 In this work, a new hybrid strengthening technique for increasing the load carrying capacity of

548 rectangular reinforced concrete (RC) columns subjected to eccentric compressive loading is presented.

549 The technique consists on combining the principles of the near surface mount (NSM) and Strip

550 Constriction (SC) strengthening techniques, to which was attributed the designation of Hybrid Strip

551 Constriction (HSC). The strengthening effectiveness of the HSC technique was assessed by performing

552 an experimental program. The influence on the strengthening effectiveness of the cross section aspect ratio $(\lambda=\mathrm{h} / \mathrm{b})$ and flexural strengthening ration of longitudinal CFRP laminates $\left(\rho_{f l}\right)$ was investigated, by having groups of RC columns of $\lambda$ equal 1, 2 and 4, and for each group a variable number of CFRP laminates. The experimental program was, therefore, composed by the following RC columns: (1) without any type of strengthening (REF); (2) strengthened according to the HSC technique with one CFRP laminate (HSC-1L); and (3) strengthened according to the HSC technique with two CFRP laminates (HSC-2L). Based on the studies presented in this paper, the following results can be pointed out:

(1) The HSC technique has demonstrated to be capable of increasing both the load carrying capacity (up to 34\%) and lateral deflection at peak load of RC columns under eccentric loading (up to 226\%).

(2) When compared to the $\lambda 1-\mathrm{REF}$ reference column, the increase in terms of maximum load was approximately $9 \%$ and $34 \%$ for the columns $\lambda 1-\mathrm{HSC}-1 \mathrm{~L}, \lambda 1-\mathrm{HSC}-2 \mathrm{~L}$ respectively. When compared to $\lambda 2$-REF column, the increase was $21 \%$ and $33 \%$ for the columns $\lambda 2-\mathrm{HSC}-1 \mathrm{~L}$ and $\lambda 2-\mathrm{HSC}-2 \mathrm{~L}$, respectively. Finally, an increase of $19 \%$ and $23 \%$ was obtained in the in the $\lambda 4-\mathrm{HSC}-1 \mathrm{~L}$ and $\lambda 4$-HSC$2 \mathrm{~L}$ when compared to the $\lambda 4$-REF. It was concluded that the strengthening effectiveness of HSC has decreased with the increase of $\lambda$, and that the failure modes observed in the three groups of columns play an important role in limiting the benefits of the proposed technique.

(3) The maximum load carrying capacity and the mid height lateral displacement at peak load of 
the increase of $\lambda$, the $\rho_{f l}$ should increase with $\lambda$, but the resulting strengthening effectiveness must be 573 weighed against the costs of the technique.

574 (4) By calculating the strength gain as the ratio between the compressive strength of a strengthened column and its corresponding reference column, it was verified that the strength gain has increased from $\lambda 1$ to $\lambda 2$, and was similar from $\lambda 2$ to $\lambda 4$. This was caused by the different level of activation of the confinement capacity of the CFRP strips, in consequence of the different types of failures modes occurred in the these three series of RC columns: concrete crushing in the $\lambda 1$; rupture of CFRP laminates in the $\lambda 2$; premature local failure mode in the $\lambda 4$.

(5) The analytical model for predicting the maximum compressive load and corresponding lateral midheight displacement of RC columns strengthened according to HSC technique has provided good agreement with the experimental results. The model has integrated a module to anticipate the occurrence of local failures modes, such as in the case of the columns of $\lambda=4$. This module is activated when the effective width $\left(b_{e f}\right)$ is less than the largest edge of the column's cross section. The proposed model was capable of predicting the maximum load carrying capacity of the tested columns with an interval error of $2 \%-10 \%$. In terms of lateral mid-height displacement at maximum compressive load, the interval error was $2 \%-65 \%$. These values demonstrate a reasonable predictive accuracy of the model, despite its simplicity and therefore, it potential to be used in the design context. However, further experimental programs with RC columns of different values of $\lambda, \rho_{f l}, f_{c m}$ and load eccentricity ratio should be performed in order to provide more results for assessing the reliability of the proposed model. Although the relevant results of the experimental program have demonstrated the efficiency of the proposed technique, further experimental programs are being planned to be executed, in order to have results with statistical representativeness on this efficiency, as well as to allow the development of a reliable design guideline. 


\section{ACKNOWLEDGEMENTS}

597 The authors acknowledge the support provided by FEDER funds through the Operational Programme

598 for Competitiveness and Internationalization Program (POCI) and by FCT (Portuguese Foundation for

599 Science and Technology) within the scope of the project StreColesf, POCI-01-0145-FEDER-029485.

600 The support provided by CASAIS Company on the production of the specimens and CiviTest

601 company on the strengthening of the columns is also acknowledged.

602

\section{DATA AVAILABILITY STATEMENT}

604

Some data that used during the study are available in a repository online in accordance with the following reference;

606

Janwaen, W., Barros, J. A. O., and Costa, I. G. 2019. "A new strengthening technique for increasing the load carrying capacity of rectangular reinforced concrete columns subjected to axial compressive loading." Composite Part B: Engineering.

Accessed

February $\quad 5, \quad 2019$. https://doi.org/10.1016/j.compositesb.2018.09.045.

610

\section{REFERENCES}

Abbasnia, R., Ahmadi, R., and Ziaadiny, H. (2012). "Effect of confinement level, aspect ratio and concrete strength on the cyclic stress-strain behavior of FRP-confined concrete prisms." Compos. Part B Eng., 43, 825-831. https://doi.org/10.1016/j.compositesb.2011.11.008.

ACI (American Concrete Institute). (2017). "Guide for the design and construction of externally bonded

Barros, J. A. O., Taheri, M., and Salehian, H. (2015). “A model to simulate the moment-rotation and crack width of FRC members reinforced with longitudinal bars.” Eng. Struct., 100, 43-56. https://doi.org/10.1016/j.engstruct.2015.05.036.

Barros, J. A. O., Varma, R. K., Sena-Cruz, J. M., and Azevedo, A. F. M. (2008). "Near surface mounted CFRP strips for the flexural strengthening of RC columns: Experimental and numerical research." Eng. Struct., 30(12), 3412-3425. https://doi.org/10.1016/j.engstruct.2008.05.019. 
Benzaid, R., Chikh, N. E., and Mesbah, H. (2008). "Behaviour of square concrete column confined with GFRP composite warp." J. Civ. Eng. Manag., 14, 115-120. https://doi.org/10.3846/13923730.2008.14.6.

Chaallal, O., Shahawy, M., and Hassan, M. (2003). "Performance of axially loaded short rectangular columns strengthened with carbon fiber-reinforced polymer wrapping." J. Compos. Constr., 10.1061/(ASCE)1090-0268(2003)7:3(200), 200-208.

Chellapandian, M., Suriya Prakash, S., and Sharma, A. (2017). "Strength and ductility of innovative hybrid NSM reinforced and FRP confined short RC columns under axial compression." Compos. Struct., 176, 205-216. https://doi.org/10.1016/j.compstruct.2017.05.033.

Ciniņa, I., Zīle, E., and Zīle, O. (2012). "Mechanical behavior of concrete columns confined by basalt FRP windings." Mech. Compos. Mater., 48(5), 539-546.

$$
\text { https://doi.org/10.1007/s11029-012-9298-y. }
$$

Colajanni, P., Fossetti, M., and MacAluso, G. (2014). "Effects of confinement level, cross-section shape and corner radius on the cyclic behavior of CFRCM confined concrete columns." Constr. Build. Mater., 55, 379-389. https://doi.org/10.1016/j.conbuildmat.2014.01.035.

Costa, I. G. and Barros, J. A. O. (2015). “Tensile creep of a structural epoxy adhesive: experimental and analytical characterization.” Int. J. Adhes. Adhes., 59, 115-124.

$$
\text { https://doi.org/10.1016/j.ijadhadh.2015.02.006. }
$$

El-Maaddawy, T. (2009). "Strengthening of eccentrically loaded reinforced concrete columns with fiber-reinforced polymer wrapping system: Experimental investigation and analytical modeling.” J. Compos. Constr., 10.1061/(ASCE)1090-0268(2009)13:1(13), 13-24.

El-Maaddawy, T., El-Sayed, M., and Abdel-Magid, B. (2010). “The effects of cross-sectional shape and loading condition on performance of reinforced concrete members confined with Carbon Fiber-Reinforced Polymers.” Mater. Des., 31(5), 2330-2341. https://doi.org/10.1016/j.matdes.2009.12.004.

Gajdosova, K., and Bilcik, J. (2013). "Full-scale testing of CFRP-strengthened slender reinforced concrete columns.” J. Compos. Constr., 10.1061/(ASCE)CC.1943-5614.0000329, 239-248. 
Hadi, M. N. S. (2007a). "Behaviour of FRP strengthened concrete columns under eccentric compression loading.” Compos. Struct., 77(1), 92-96. https://doi.org/10.1016/j.compstruct.2005.06.007.

Hadi, M. N. S. (2007b). “The behaviour of FRP wrapped HSC columns under different eccentric loads.” Compos. Struct., 78(4), 560-566. https://doi.org/10.1016/j.compstruct.2005.11.018.

Harajli, M. H. (2006). "Axial stress-strain relationship for FRP confined circular and rectangular concrete columns." Cem. Concr. Compos., 28(10), 938-948. https://doi.org/10.1016/j.cemconcomp.2006.07.005.

Hollaway, L. C., and Teng, J. G. (2008). Strengthening and rehabilitation of civil infrastructures using fibre-reinforced polymer (FRP) composites, Woodhead Publishing Limited, Cambridge, England.

ISO (International Organization for Standardization). (1993). "Plastics-determination of tensile properties-part 2: test conditions for moulding and extrusion plastics." ISO-527-2, Geneva, Switzerland.

ISO (International Organization for Standardization). (2009a). "Metallic materials - tensile testing— part 1: method of test at room temperature." ISO-6892-1, Geneva, Switzerland.

ISO (International Organization for Standardization). (2009b). "Plastics-determination of tensile properties-part 5: test conditions for unidirectional fibre-reinforced plastic composites." ISO527-5, Geneva, Switzerland.

Janke, L., Czaderski, C., Ruth, J., and Motavalli, M. (2009). "Experiments on the residual load-bearing capacity of prestressed confined concrete columns." Eng. Struct., 31, 2247-2256. https://doi.org/10.1016/j.engstruct.2009.04.006.

Janwaen, W., Barros, J. A. O., and Costa, I. G. (2019). “A new strengthening technique for increasing the load carrying capacity of rectangular reinforced concrete columns subjected to axial compressive loading." Compos. Part B Eng., 158, 67-81. https://doi.org/10.1016/j.compositesb.2018.09.045.

Liang, Q. Q. (2011). “High strength circular concrete-filled steel tubular slender beam-columns, Part I: Numerical analysis." J. Constr. Steel Res., 67(2), 164-171. https://doi.org/10.1016/j.jcsr.2010.08.006. 
Mander, J. B., Priestley, M. J., and Park, R. (1988). "Theoretical stress-strain model for confined concrete.” J. Struct. Eng., 10.1061/(ASCE)0733-9445(1988)114:8(1804), 1804-1825.

Matthys, S., Toutanji, H., Audenaert, K., and Taerwe, L. (2005). "Axial load behavior of large-scale columns confined with fiber-reinforced polymer composites.” ACI Struct. J., 102(2), 258-267. https://doi.org/10.14359/14277.

Mirmiran, A., Shahawy, M., Samaan, M., El Echary, H., Mastrapa, J. C., and Pico, O. (1998). "Effect of column parameters on FRP-confined concrete.” J. Compos. Constr., 10.1061/(ASCE)10900268(1998)2:4(175), 175-185.

Nesheli, K.N. and Meguro, K. (2005). "External Prestressing Concrete Columns with Fibrous Composite Belts.” ACI Symp. Publ., 230, 1631-1646.

Nisticò, N., Pallini, F., Rousakis, T., Wu, Y. F., and Karabinis, A. (2014). "Peak strength and ultimate strain prediction for FRP confined square and circular concrete sections." Compos. Part B Eng., 67, 543-554. https://doi.org/10.1016/j.compositesb.2014.07.026.

Pan, J. L., Xu, T., and Hu, Z. J. (2007). "Experimental investigation of load carrying capacity of the slender reinforced concrete columns wrapped with FRP.” Constr. Build. Mater., 21, 1991-1996. https://doi.org/10.1016/j.conbuildmat.2006.05.050.

Perrone, M., Barros, J. A. O., and Aprile, A. (2009). “CFRP-based strengthening technique to increase the flexural and energy dissipation capacities of RC Columns." J. Compos. Constr., 10.1061/(ASCE)CC.1943-5614.0000031, 372-383.

Popovics, S. (1973). "A numerical approach to the complete stress-strain curve of concrete." Cem. Concr. Res., 3(5), 583-599. https://doi.org/10.1016/0008-8846(73)90096-3.

Rochette, P., and Labossière, P. (2000). "Axial testing of rectangular column models confined with composites.” J. Compos. Constr., 10.1061/(ASCE)1090-0268(2000)4:3(129), 129-136.

Rousakis, T. C., and Tourtouras, I. S. (2014). "RC columns of square section - Passive and active confinement with composite ropes." Compos. Part B Eng., 58, 573-581. https://doi.org/10.1016/j.compositesb.2013.11.011. 
Rousakis, T. C., Panagiotakis, G. D., Archontaki, E. E., and Kostopoulos, A. K. (2019). "Prismatic RC columns externally confined with FRP sheets and pre-tensioned basalt fiber ropes under cyclic axial load.” Compos. Part B Eng., 163, 96-106. https://doi.org/10.1016/j.compositesb.2018.11.024.

707

Shan, B., Gui, F.C., Monti, G. and Xiao, Y. (2017). "Effectiveness of CFRP Confinement and 708 Compressive Strength of Square Concrete Columns." J. Compos. Constr., 10.1061/(ASCE)CC.1943-5614.0000967, 04019043.

Tamuzs, V., Tepfers, R., You, CS., Rousakis, T., Repelis, I., Skruls, V., et al. (2006). "Behavior of concrete cylinders confined by carbon-composite tapes and prestressed yarns 1 . Experimental data.” Mech. Compos. Mater., 41(1), 13-32. https://doi.org/10.1007/s11029-006-0013-8.

Yang, X., Wei, J., Nanni, A., and Dharani, L. R. (2004). "Shape effect on the performance of carbon fiber-reinforced polymer wraps.” J. Compos. Constr., 10.1061/(ASCE)1090-0268(2004)8:5(444), $444-451$.

Zeng, J. J., Guo, Y. C., Gao, W. Y., Li, J. Z., and Xie, J. H. (2017). "Behavior of partially and fully FRP-confined circularized square columns under axial compression.” Constr. Build. Mater., 152, 


\section{FIGURES}

\section{$721 \quad$ List of Figures}

722 Fig. 1 - Geometry, reinforcement, and strengthening configuration for the series of RC columns with cross-sectional aspect ratio of: a) 1; b) 2; and c) 4 (dimension in $\mathrm{mm}$ )

724 Fig. 2 - Schematic representation of the new hybrid strengthening technique (HSC)

725 Fig. 3 - Test setup and monitoring system (dimensions in $\mathrm{mm}$ )

726 Fig. 4 - Failure modes of the columns with cross-section aspect ratio $(\lambda)$ equal to 1

727 Fig. 5 - Failure modes of the columns with cross-section aspect ratio $(\lambda)$ equal to 2

728 Fig. 6 - Failure modes of the columns with cross-section aspect ratio $(\lambda)$ equal to 4

729 Fig. 7 - Axial compressive load versus lateral mid-height displacement in the RC columns of cross-

730 section aspect ratio ( $\lambda$ ) of: a) 1 ; b) 2 ; and c) 4

731 Fig. 8 - Compressive strength of columns versus cross-section aspect ratio

732 Fig. 9 - Compressive strength gain versus cross-section aspect ratio

733 Fig. 10 - Stress-strain diagram for confined concrete in rectangular RC columns

734 Fig. 11 - Assumed lateral deformation shape for eccentrically loaded columns

$735 \quad$ Fig. 12 - Layered cross section approach

736 Fig. 13 - Flow chart of the algorithm of the model

737 Fig. 14 - Schematic representation of failure mechanism of $\lambda 4-R E F$ at critical plane

738 Fig. 15 - Schematic represent of failure mechanism of $\lambda 4$-HSC at critical plane

739 Fig. 16 - Comparison between analytical and experimental results in terms of axial compressive load

740 versus lateral mid-height displacement for the columns with cross-section aspect ratio of 1

741 Fig. 17 - Comparison between analytical and experimental results in terms of axial compressive load

742 versus lateral mid-height displacement for the columns with cross-section aspect ratio of 2

743 Fig. 18 - Comparison between analytical and experimental results in terms of axial compressive load versus lateral mid-height displacement for the columns with cross-section aspect ratio of 4 


\section{List of tables:}

Table 1 - Material properties of steel reinforcement (average values of three specimens)

Table 2 - Material properties of CFRP sheet (provided by manufacturer)

753 Table 4 - Summary of experimental results for evaluating the strength gain of columns 
758 Table 1 - Material properties of steel reinforcement (average values of three specimens)

\begin{tabular}{lll}
\hline Property & $\phi 6 \mathrm{~mm}$ & $\phi 10 \mathrm{~mm}$ \\
\hline Yield stress (MPa) & 580 & 452 \\
Tensile strength (MPa) & 664 & 545 \\
Modulus of elasticity (GPa) & 200 & 205 \\
Ultimate tensile strain & 0.064 & 0.124 \\
\hline
\end{tabular}

759

760 
761 Table 2 - Material properties of CFRP sheet (provided by manufacturer)

\begin{tabular}{ll}
\hline Property & CFRP sheet \\
\hline Tensile strength $(\mathrm{MPa})$ & 3800 \\
Tensile modulus $(\mathrm{GPa})$ & 240 \\
Elongation at rupture $(\%)$ & 1.55 \\
Weight per unit area of sheet $\left(\mathrm{g} / \mathrm{m}^{2}\right)$ & 230 \\
Thickness of the ply $(\mathrm{mm})$ & 0.117 \\
\hline
\end{tabular}

762

763 
764 Table 3 - Summary of experimental results for all eccentrically loaded columns

\begin{tabular}{|c|c|c|c|c|c|}
\hline Column ID & $\lambda=h / b$ & Eccentricity $(e)$ & $\begin{array}{l}\text { Maximum compressive } \\
\text { load }\left(P_{\max }\right) \\
(\mathrm{kN})\end{array}$ & $\begin{array}{c}\text { Lateral mid-height } \\
\text { displacement at } P_{\max } \\
\left(u_{\max }\right) \\
(\mathrm{mm})\end{array}$ & $\Delta P_{\text {max }}$ \\
\hline$\lambda 1-\mathrm{REF}$ & \multirow{4}{*}{1} & \multirow{4}{*}{18} & 321 & 4.05 & - \\
\hline$\lambda 1-\mathrm{HSC}-1 \mathrm{~L}$ & & & 349 & 7.15 & 8.7 \\
\hline$\lambda 1$-HSC-2L-1 & & & 428 & 10.99 & 33.3 \\
\hline$\lambda 1-\mathrm{HSC}-2 \mathrm{~L}-2$ & & & 432 & 13.08 & 34.6 \\
\hline$\lambda 2$-REF & \multirow{4}{*}{2} & \multirow{4}{*}{36} & 577 & 2.02 & - \\
\hline$\lambda 2-\mathrm{HSC}-1 \mathrm{~L}$ & & & 697 & 4.03 & 20.8 \\
\hline$\lambda 2$-HSC-2L-1 & & & 762 & 5.32 & 32.1 \\
\hline$\lambda 2-\mathrm{HSC}-2 \mathrm{~L}-2$ & & & 778 & 6.45 & 34.8 \\
\hline$\lambda 4-\mathrm{REF}$ & \multirow{4}{*}{4} & \multirow{4}{*}{72} & 892 & 0.43 & - \\
\hline$\lambda 4$-HSC-1L & & & 1062 & 1.16 & 19.1 \\
\hline$\lambda 4$-HSC-2L-1 & & & 1123 & 1.36 & 25.9 \\
\hline$\lambda 4$-HSC-2L-2 & & & 1072 & 1.45 & 20.2 \\
\hline
\end{tabular}


767 Table 4 - Summary of experimental results for evaluating the strength gain of columns

\begin{tabular}{|c|c|c|c|c|c|c|}
\hline Column ID & $\begin{array}{l}A_{e f f} \\
\left(\mathrm{~mm}^{2}\right)\end{array}$ & $\begin{array}{l}P_{\max } \\
(\mathrm{kN})\end{array}$ & $\begin{array}{c}\sigma_{c c, \max } \\
(\mathrm{MPa})\end{array}$ & $\begin{array}{c}\sigma_{c c, \text { max }}^{a v g} \\
(\mathrm{MPa})\end{array}$ & $\sigma_{c c, \max }^{S t r} / \sigma_{c c, \max }^{R e f}$ & $\Delta \sigma_{c c, \max }^{S t r, \rho_{f l}}$ \\
\hline$\lambda 1-\mathrm{REF}$ & 14400 & 321 & 22.3 & 22.3 & - & - \\
\hline$\lambda 1-\mathrm{HSC}-1 \mathrm{~L}$ & 13864 & 349 & 25.2 & 25.2 & 1.13 & \multirow{3}{*}{0.26} \\
\hline$\lambda 1-\mathrm{HSC}-2 \mathrm{~L}-1$ & 13864 & 428 & 30.9 & \multirow{2}{*}{31.1} & \multirow{2}{*}{1.39} & \\
\hline$\lambda 1$-HSC-2L-2 & 13864 & 432 & 31.2 & & & \\
\hline$\lambda 2-\mathrm{REF}$ & 28800 & 577 & 20.0 & 20.0 & - & - \\
\hline$\lambda 2-\mathrm{HSC}-1 \mathrm{~L}$ & 27192 & 697 & 25.6 & 25.6 & 1.28 & \multirow{3}{*}{0.13} \\
\hline$\lambda 2-\mathrm{HSC}-2 \mathrm{~L}-1$ & 27192 & 762 & 28.0 & \multirow{2}{*}{28.3} & \multirow{2}{*}{1.41} & \\
\hline$\lambda 2$-HSC-2L-2 & 27192 & 778 & 28.6 & & & \\
\hline$\lambda 4-\mathrm{REF}$ & 57600 & 892 & 15.5 & 15.5 & - & - \\
\hline$\lambda 4-\mathrm{HSC}-1 \mathrm{~L}$ & 53850 & 1062 & 19.7 & 19.7 & 1.27 & \multirow{3}{*}{0.05} \\
\hline$\lambda 4$-HSC-2L-1 & 53850 & 1123 & 20.9 & \multirow{2}{*}{20.4} & 127 & \\
\hline$\lambda 4-\mathrm{HSC}-2 \mathrm{~L}-2$ & 53850 & 1072 & 19.9 & & 1.32 & \\
\hline
\end{tabular}


770 Table 5 - Comparison between analytical predictions and experimental results

\begin{tabular}{|c|c|c|c|c|c|c|}
\hline \multirow[t]{2}{*}{ Column ID } & \multicolumn{2}{|c|}{ Maximum compressive load } & \multirow{2}{*}{$\begin{array}{l}\text { Strength } \\
\text { error } \\
\\
(\%)\end{array}$} & \multicolumn{2}{|c|}{$\begin{array}{l}\text { Lateral mid-height displacement } \\
\text { at maximum load }\end{array}$} & \multirow{2}{*}{$\begin{array}{c}\text { Deflection error } \\
(\%)\end{array}$} \\
\hline & $\begin{array}{c}\text { Experimental, } \\
P_{\text {exp }} \\
(\mathrm{kN})\end{array}$ & $\begin{array}{c}\text { Analytical, } \\
P_{\text {ana }} \\
(\mathrm{kN})\end{array}$ & & $\begin{array}{c}\text { Experimental, } \\
u_{\text {exp }} \\
(\mathrm{mm})\end{array}$ & $\begin{array}{c}\text { Analytical, } \\
u_{\text {ana }} \\
(\mathrm{mm})\end{array}$ & \\
\hline$\lambda 1-\mathrm{REF}$ & 321 & 289 & -10.0 & 4.05 & 4.98 & 23.0 \\
\hline$\lambda 1-\mathrm{HSC}-1 \mathrm{~L}$ & 349 & 343 & -1.7 & 7.15 & 7.32 & 2.4 \\
\hline$\lambda 1-\mathrm{HSC}-2 \mathrm{~L}-1$ & 428 & 406 & -5.1 & 10.99 & 18.21 & 65.7 \\
\hline$\lambda 1-\mathrm{HSC}-2 \mathrm{~L}-2$ & 432 & 406 & -6.0 & 13.08 & 18.21 & 39.2 \\
\hline$\lambda 2-\mathrm{REF}$ & 577 & 562 & -2.6 & 2.02 & 1.90 & -5.9 \\
\hline$\lambda 2-\mathrm{HSC}-1 \mathrm{~L}$ & 697 & 680 & -2.4 & 4.03 & 5.79 & 43.7 \\
\hline$\lambda 2$-HSC-2L-1 & 762 & 775 & 1.7 & 5.23 & 7.03 & 32.1 \\
\hline$\lambda 2-H S C-2 L-2$ & 778 & 775 & -0.4 & 6.45 & 7.03 & 9.0 \\
\hline$\lambda 4-\mathrm{REF}$ & 892 & 892 & 0.0 & 0.43 & 0.56 & 30.2 \\
\hline$\lambda 4-\mathrm{HSC}-1 \mathrm{~L}$ & 1062 & {$[1069 ; 1142]$} & {$[0.6 ; 7.5]$} & 1.16 & {$[0.92 ; 1.18]$} & {$[-20.7 ; 1.7]$} \\
\hline$\lambda 4$-HSC-2L-1 & 1123 & {$[1069 ; 1142]$} & {$[-4.8 ; 1.7]$} & 1.36 & {$[0.84 ; 1.03]$} & {$[-38.2 ;-24.3]$} \\
\hline$\lambda 4$-HSC-2L-2 & 1072 & {$[1069 ; 1142]$} & {$[-0.3 ; 6.5]$} & 1.45 & {$[0.84 ; 1.03]$} & {$[-42.1 ;-29.0]$} \\
\hline
\end{tabular}

771 Strength Error $(\%)=100 \times\left(P_{\text {ana }}-P_{\exp }\right) / P_{\exp }$

772 Deflection error $(\%)=100 \times\left(u_{a n a}-u_{\exp }\right) / u_{\exp }$

773 Values in brackets: obtained when assuming for the $\theta_{2}$ following two values $\left[37^{\circ} ; 40^{\circ}\right]$ 